CDD: 184

\title{
Copresença de opostos em República V, 478e-480a ${ }^{*}$
}

\section{Breno Andrade Zuppolini}

Universidade Estadual de Campinas

Instituto de Filosofia e Ciências Humanas

Cidade Universitária Zeferino $V$ az.

13083-896 Campinas, SP, Brasil

baz1289@gmail.com

Received: 15.12.2014; Revised: 13.10.2015; Accepted: 19.10.2015

DOI: http://dx.doi.org/10.1590/0100-6045.2015.V38N3.BAZ

Resumo: Pretendemos aqui analisar o texto de República V, 478e-480a, em que Platão argumenta contra um adversário que rejeita a teoria das Formas e restringe o domínio do conhecimento a itens sensíveis. O argumento de Platão conclui que seu adversário não pode ter conhecimento, mas somente opinião. O raciocínio baseia-se em uma premissa que afirma que os objetos sensíveis, ao contrário das Formas, estariam submetidos a uma certa copresença de atributos opostos. Apresentamos uma versão do argumento visando dois propósitos centrais: por um lado, buscamos resolver certas dificuldades textuais e teóricas que o leitor da passagem tem de enfrentar; por outro, evitamos comprometer Platão com a tese de que os itens sensíveis estão excluídos do domínio do conhecimento. Nossa estratégia envolve argumentar que a passagem assume um esquema conceitual que não é o de Platão, mas o de seu adversário.

Palavras-chave: Platão; Formas; Ontologia; Epistemologia.

\footnotetext{
* Registro aqui minha gratidão a Gustavo Bianchi Ferreira, Natalia Costa Rugnitz e Anderson de Paula Borges pelos cuidadosos comentários a uma versão prévia deste artigo. Agradeço ainda ao Anderson Borges pelas referências bibliográficas e, a Gustavo Ferreira e Lucas Angioni, pelas várias discussões informais sobre o tema. Sou grato também a dois pareceristas anônimos por preciosas sugestões.
}

Manuscrito - Rev. Int. Fil., Campinas, v. 38, n.3, pp. 81-110, set.-dez. 2015. 


\title{
Compresence of opposites in Republic V, 478e-480a
}

\begin{abstract}
We intend to analyse the text of Republic V, 478e-480a, in which Plato argues against an opponent who rejects the theory of Forms and confines the domain of knowledge to sensible items. Plato's argument concludes that his opponent cannot have knowledge, but only opinion. The reasoning relies on a premise stating that the sensible objects, unlike the Forms, suffer a certain compresence of opposite attributes. We present a version of the argument with two aims in mind: on one hand, we intend to solve a set of textual and theoretical difficulties that the reader of the passage has to face; on the other, we avoid committing Plato to the thesis that sensible items are excluded from the domain of knowledge. Our strategy involves arguing that the passage assumes a conceptual framework that belongs not to Plato, but to his opponent.
\end{abstract}

Keywords: Plato; Forms; Ontology; Epistemology.

No final do livro V da República, Platão ocupa-se da distinção entre conhecimento ( $\dot{\tau} \pi \iota \tau \tau^{\prime} \mu \eta \eta$ ) e opinião ( $\left.\delta o^{\prime} \xi \alpha\right)$. O filósofo ali argumenta contra um adversário descrito como um 'amante' de sons e imagens (476b4), cujo comprometimento ontológico não vai além do domínio do sensível e que, portanto, recusa a existência das Formas. Na falta de melhor nomenclatura, nós o denominaremos 'o amante dos sentidos'. ${ }^{1}$ No último estágio de sua argumentação, em 478e7-480a4, Platão argumenta que os sensíveis estão entre o 'ser' e o 'não ser' para, então, concluir que o amante dos sentidos pode ter apenas opinião do que quer que venha a investigar, mas jamais conhecimento (479e1-5). A razão alegada é o fato do conhecimento ser sempre sobre algo que 'é' (476e1011), enquanto aquilo que 'é e não é’ só pode ser objeto de opinião (478e1-5).

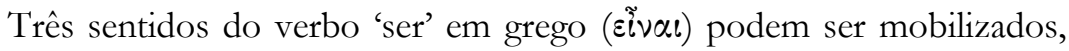
com alguma razoabilidade, para caracterizar o conhecimento de 'algo que é'. Um

\footnotetext{
${ }^{1}$ Advertimos, desde já, que esta não é uma tradução para a expressão grega ' $\varphi$ ı $\lambda 0 \theta \varepsilon \alpha ́ \mu \omega \nu$ ' ('amante de espetáculos' ou 'amante das visões'), pela qual Platão se refere a seu adversário na maioria das vezes. Trata-se apenas de um rótulo geral para todos os que se apegam os sentidos e rejeitam a existência das Formas, sejam eles 'amantes de audições'

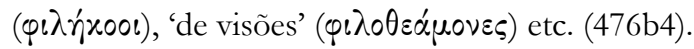

Manuscrito - Rev. Int. Fil., Campinas, v. 38, n.3, pp. 81-110, set.-dez. 2015. 
deles é existencial (conhece-se algo que existe), outro veritativo (conhece-se algo verdadeiro) e um terceiro é predicativo ou copulativo (conhece-se que algo é F).

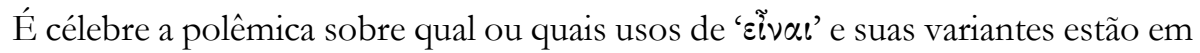
questão ao longo de Rep. V, especialmente a partir de 476e. Contudo, há pouca controvérsia sobre qual dos sentidos ocorre em 478e 7-480a4. Como evidenciam as linhas 479a5-8 e 479b8-9, Platão notadamente faz uso copulativo do verbo (ver Vlastos 1973b, p. 63, n. 21; Annas 1981, p. 198; Shields 2003, p. 72). Mesmo intérpretes que insistiram na predominância do sentido veritativo em passagens anteriores admitem que é a acepção predicativa que ocorre nesta etapa final da argumentação (ver Fine 2003b, p. 77-78). Portanto, locuções como 'x participa do ser e do não-ser' (478e1-2; 479b7) e 'x está entre ser e não ser' (479c7; d3) significam mais propriamente 'x participa do ser-F e do não-ser-F' e 'x está entre ser F e não ser F' (ver Gosling 1960, pp. 126-127). Sendo assim, o argumento pode ser reconstruído esquematicamente nos seguintes termos:

(1) Se algo participa do 'ser' (ser F) e do 'não ser' (não ser F), então, é objeto de opinião, não conhecimento (478e1-5).

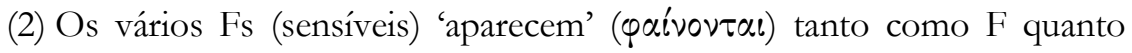
como não-F (479a5-b3).

(3) Os vários Fs (sensíveis) participam tanto do 'ser' (ser F) quanto do 'não ser' (não ser F) (479b7; c6-7).

(4) Os vários Fs (sensíveis) são objetos de opinião, não conhecimento (479d10-e4).

Não é claro o que as premissas significam, o que nos impede de avaliar, de saída, se o argumento de Platão é correto ${ }^{2}$ ou, ao menos, válido. Entretanto, a conclusão (4) por si mesma já se impõe como um problema. É fato que a interpretação ortodoxa da relação entre a metafísica e a epistemologia de Platão entende que, para o filósofo, os objetos sensíveis estão definitivamente excluídos do domínio do conhecimento. Com efeito, já no segundo argumento contra o amante dos sentidos (476e4-478e6), o filósofo argumenta que a capacidades cognitivas distintas (como conhecimento e opinião) correspondem domínios 2 Usarei a expressão 'argumento correto' como tradução para 'sound argument', isto é,
argumento válido com premissas verdadeiras.

Manuscrito - Rev. Int. Fil., Campinas, v. 38, n.3, pp. 81-110, set.-dez. 2015. 
distintos de objetos. Entretanto, a ideia de que Platão separou o domínio da opinião e o domínio do conhecimento de tal modo que não haveria intersecção entre os dois foi persuasivamente criticada por parte da literatura secundária. ${ }^{3}$ Argumentou-se em favor da hipótese de que Platão teria sim reconhecido a cognoscibilidade dos sensíveis e apenas a condicionado ao conhecimento das Formas (ver Fine 2003b; Fine 2003c). O princípio de caridade nos convida a preferir uma versão da metafísica platônica que não implique uma redução do escopo do conhecimento tão severa a ponto de excluir de seu universo de discurso os objetos particulares do senso comum. Todavia, o propósito mesmo do argumento de 478e7-480a4 parece ser o de localizar os sensíveis exclusivamente na alçada da opinião.

Pretendemos, neste artigo, fornecer uma interpretação de 478e7-480a4 que não impute a Platão a inconveniente visão de que os elementos do mundo sensível não podem ser conhecidos. Ao mesmo tempo, procuraremos resolver duas dificuldades cruciais que o texto suscita ao leitor moderno, as quais não foram, a nosso ver, satisfatoriamente resolvidas pelos intérpretes que defenderam a cognoscibilidade dos sensíveis em Platão. Após uma análise preliminar das premissas (2) e (3) e da assim chamada tese da 'copresença de opostos', na seção I, exporemos estas dificuldades na seção II. Na seção III, defenderemos uma solução para uma das duas dificuldades mencionadas, reconstituindo o esquema conceitual com o qual o argumento de Rep. V opera, cujas teses e conceitos devem ser atribuído não a Platão, mas a seu adversário (ou assim argumentaremos). Prosseguiremos na seção IV com a solução da segunda dificuldade elencada na seção II, indicando de que modo as noções de explicação e definição atuam no pano de fundo do argumento de Platão contra o amante dos sentidos. Concluiremos nossa discussão na seção V.

\section{Copresença de Opostos e Dependência Contextual}

A conclusão (4) do argumento esquematizado acima é obtenível por modus ponens a partir de (1) e (3). No entanto, o sucesso do argumento depende ainda de inferência da premissa (3) a partir de (2), passo cuja validade não é clara

\footnotetext{
${ }^{3}$ Ver Irwin (1977), Irwin (1999), Annas (1981) e, mais notadamente, Fine (2003b) e Fine (2003c).
}

Manuscrito - Rev. Int. Fil., Campinas, v. 38, n.3, pp. 81-110, set.-dez. 2015. 
à primeira vista. 'Aparecer', em (2), traduz ' $\varphi \alpha$ i $v \varepsilon \sigma \theta \alpha$ ' do grego, que ocorre em

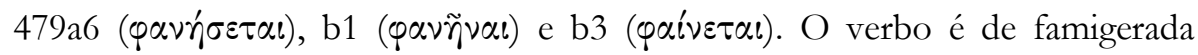
ambiguidade. Ao incidir sobre um dado conteúdo predicativo-proposicional,

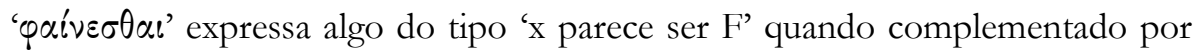
uma forma infinitiva do verbo 'ser' (ou qualquer outro verbo capaz de desempenhar a função lógica de cópula). Quando associado a um particípio, o verbo tem um sentido verídico e deve ser interpretado como significando que $\mathrm{x}$ é 'claramente' ou 'evidentemente' F ou ainda que x 'mostra-se' ou 'revela-se' como F. Contudo, nenhuma das ocorrências de ' $\varphi \alpha$ ' $v \varepsilon \sigma \theta \alpha \iota$ ' no argumento é acompanhada nem por um infinitivo, nem por um particípio, de tal modo que não temos nenhuma razão gramatical para decidir em favor de uma ou outra interpretação.

Há, no entanto, uma razão exegética para optar pelo sentido verídico. Caso as ocorrências do verbo ' $\varphi \alpha$ ' $v \varepsilon \sigma \theta \alpha \iota$ ' no argumento fossem interpretadas segundo a noção de aparência, a premissa (2) consistiria em uma asserção de caráter puramente epistemológico: qualquer item sensível x que aparente ser $\mathrm{F}$ aparentará também ser não-F. Esta tese é controversa o suficiente para não a aceitarmos sem boas razões. Mais difícil, porém, é identificar o que nos autorizaria a inferir a partir dela uma conclusão ainda mais forte e de evidente importe metafísico. Com efeito, (3) diz respeito ao 'ser' mais do que ao 'parecer ser' e os objetos sensíveis já haviam sido localizados entre aquilo que "é de maneira pura" e aquilo que "não é de modo algum" (478d5-9). Ademais, tanto Sócrates quanto Glauco fazem uso do jargão metafísico da 'participação'

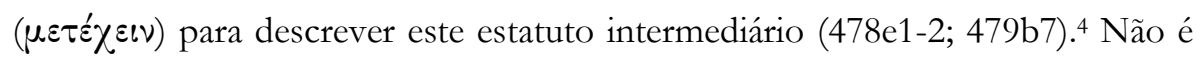

\footnotetext{
${ }^{4}$ Ver Bostock (1986, pp. 75-78). Uma explicação que mantém o sentido não-verídico do verbo foi proposta por Svavarsson (2009, p. 74), segundo a qual Platão supõe que os sensíveis não podem ser conhecidos como $\mathrm{F}$ ou não-F justamente porque variavelmente parecem F e não-F. Segundo a República, o real seria cognoscível e o irreal não o seria, de tal modo que, "se algo não é cognoscível como F, então, não é realmente F" (id.ibid.). Esta saída, ainda que fácil, não é de todo satisfatória. Em primeiro lugar, ela supõe que, mesmo para aquele que admite a existência das Formas e as conhece, os sensíveis não são objeto de conhecimento, mas apenas de opinião, o que não parece um resultado desejável. Ademais, ainda restaria totalmente obscura a razão pela qual aparências conflitantes só ocorrem àquilo que é 'menos real'. Embora as Formas não se apresentem
} 
sem razão, portanto, que muitos acreditam que o argumento final de Rep. V faz uso de uma indigesta tese, comumente atribuída a Platão, que reconhece no mundo sensível a ocorrência de um fenômeno usualmente denominado 'Copresença de Opostos' (doravante, CO): x é não-F.

CO: para todo item sensível x e qualquer propriedade F, se x é F, então,

Se a CO é de fato mobilizada por Platão em seu ataque ao amante dos sentidos (como o vocabulário metafísico utilizado indica), parece conveniente interpretar as mencionadas ocorrências de ' $\varphi \alpha$ i $v \varepsilon \sigma \theta \alpha$ ' como conotando mais do que mera e falível aparência. ${ }^{5}$

A tese da CO é em geral sustentada com o auxílio de exemplos de predicados com características bastante precisas. Alguns deles são relacionais, como 'dobro', 'metade' (Rep. 479b2-3), 'igual', 'desigual' (Fédon 74b8), 'maior', 'menor' (Fédon 102b3-5), 'semelhante', 'dessemelhante' (Parmênides 129d6), entre outros. Em Fédon 102b4-6, é possível assimilar o que motivou Platão a ver nos predicados relacionais uma corroboração da tese da CO: "Quando afirmas que Símias é mais alto do que Sócrates e mais baixo do que Fédon, dizes que ambos se encontram em Símias, tanto a grandeza quanto a pequenez? - Digo sim." Este arrazoado soa ingênuo ou mesmo falacioso aos ouvidos do leitor versado em lógica moderna, para o qual relações são predicados de aridade $n>1$. Entendidos como funções binárias, predicados comparativos como 'mais alto' e 'mais baixo' só engendram proposição quando associados a pares ordenados do tipo 〈Símias, Sócrates〉 e 〈Símias, Fédon〉. Contudo, Platão aparentemente acreditou que

aos sentidos, mas ao intelecto, ainda é possível estar errado sobre elas, a despeito de seu estatuto ontológico. Não é claro, enfim, por que a noção de 'aparência' envolvida neste uso de ' $\varphi \alpha i ́ v \varepsilon \sigma \theta \alpha \iota$ ' não se aplicaria igualmente ao domínio do inteligível (ver, por exemplo, Rep. VI, 506d5-e3.

${ }^{5}$ Como ficará mais claro adiante, isso não significa que a noção de aparência não esteja em questão. Para o amante dos sentidos, $x$ parecer $F$ a alguém (fato que o grego expressaria com um complemento no infinitivo para o verbo ' $\varphi \alpha$ ' $\nu \varepsilon \sigma \theta \alpha \iota$ ') implica que $\mathrm{x}$ é, de fato, F. Portanto, o uso de um complemento no infinitivo não necessariamente

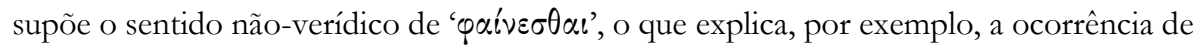
'Eivvaı' em Fédon 74d6. 
'Símias é mais alto do que Sócrates' e 'Símias é mais baixo do que Fédon' implicam que 'Símias é alto' e 'Símias é baixo' respectivamente, em que 'alto' e 'baixo' ocorrem como predicados unários. Raciocínio semelhante teria levado Platão a crer que, se um lenho x é 'igual' a um lenho y, mas não a um lenho z, x seria tanto 'igual' quanto 'desigual' (Fédon 74b7-9). ${ }^{6}$ Portanto, a única razão pela qual relações seriam exemplos paradigmáticos da $\mathrm{CO}$ parece provir da maneira precária com que Platão as teria concebido, o que levou alguns intérpretes a acusarem-no de não possuir uma teoria de enunciados relacionais. ${ }^{7}$ Outros chegam a afirmar que este grupo de predicados prestaram um desserviço aos seus propósitos teóricos e não deveriam ter papel algum na caracterização do contraste entre as Formas e o mundo sensível (ver Vlastos 1973b, pp. 72-73).

Infelizmente, nosso desconforto não é amenizado pelos outros exemplos de Platão. Entre estes costumamos encontrar adjetivos que atualmente classificaríamos como 'atributivos': 'grande', 'pequeno', 'leve', 'pesado' (Rep. V, 479b5-6), 'quente', 'frio' (Fédon 103c10-11), 'grosso', 'fino', 'duro', 'macio' (Rep. VII, 523e3-4) etc. Em um conhecido artigo, P. Geach (1956) traça uma distinção entre adjetivos atributivos e predicativos. Um adjetivo ' $F$ ' será predicativo se um enunciado da forma ' $x$ é um(a) G F', em que ' $G$ ' for um substantivo, implicar que 'x é $F$ ' e 'x é G'; caso contrário, 'F' será atributivo. Da constatação de que $x$ é uma mosca grande, exemplifica Geach (op.cit., p.33), podemos inferir que x é uma mosca, mas não que $\mathrm{x}$ é grande. Não fosse assim, adverte o autor, um simples argumento provaria que uma mosca grande é um animal grande e que um elefante pequeno é um animal pequeno (id.ibid.). No entanto, Platão aparentemente não atentou para esta distinção, pois parece acreditar que adjetivos atributivos respaldam a tese da $\mathrm{CO}$. Seus usos estão sempre associados, de modo tácito ou explícito, a um substantivo que nos fornece uma espécie de padrão ou escala de acordo com o qual a atribuição em questão é avaliada. ${ }^{8}$

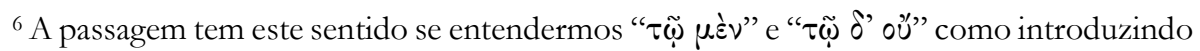
dois itens distintos como o segundo argumento de uma relação de igualdade, como propõem Murphy (1951, p. 111, n. 1), Owen (1957, p. 108, n. 33); Allen (1961, p. 330, n. 7). Cf. Mills (1957, p. 129ss.).

${ }^{7}$ Para referências e para uma rejeição desta interpretação, ver Matthen (1982).

8 Alguns intérpretes inclusive defenderam que alguns adjetivos atributivos são, na realidade, adjetivos comparativos disfarçados (Owen 1957, p.108; Gallop 1975, p.193): 
Contudo, a tese da $\mathrm{CO}$ assume que o fato de um x qualquer ser $\mathrm{F}$ de acordo com um certo parâmetro e ser não-F de acordo com um outro implica que F e não-F são ambas propriedades de $\mathrm{x}$.

Expressões relacionais e atributivas pertencem a uma classe mais abrangente de termos que alguns intérpretes denominaram 'predicados incompletos' (Owen 1957; Brentlinger 1972; Kirwan 1974; Nehamas 1999). Estes são tais que sua atribuição a um dado sujeito não pode ser avaliada sem qualificação ulterior, caracterizando-se por uma dependência contextual. Para o leitor familiarizado com o tratamento que a lógica moderna dispensa ao conceito de relação, a sentença 'Símias é mais alto do que Sócrates' não é mais sobre Símias do que sobre Sócrates. O fato do nome próprio 'Símias' ocorrer como sujeito gramatical é apenas um dado enganador da linguagem ordinária que não deve nos impedir de identificar a autêntica forma lógica da proposição, na qual uma relação binária é atribuída a um par ordenado de objetos. Por outro lado, no diálogo Fédon, Símias ser mais alto do que Sócrates e Sócrates ser mais baixo do que Símias são tratados como fatos distintos: o primeiro é sobre Símias e sua grandeza; o segundo, sobre Sócrates e sua pequenez (100e8-101b2). Por isso, como propôs Matthen (1982, pp. 94-97), as passagens em que a tese da CO está em questão parecem pressupor uma análise de predicados relacionais em que sentenças como 'Símias é mais alto do que Sócrates' correspondem prontamente à sua estrutura gramatical e contêm três elementos: um sujeito lógico ('Símias'), um predicado ('alto') e uma cláusula qualificadora ('com respeito a Sócrates').9

Semelhantemente, quando aplicamos a um dado sujeito um adjetivo atributivo (como 'grande'), o substantivo que inevitavelmente o acompanha (como 'mosca' ou 'animal') pode ser entendido como uma qualificação da relação predicativa que pretendemos expressar, fornecendo o parâmetro segundo o qual a proposição deve ser avaliada. Esta forma de atribuição qualificada pode ser facilmente rastreada nos demais exemplos invocados em favor da tese da CO. Predicados como 'bom', 'mau' (Fédon 75d1; Parmênides 103b), 'belo' e 'feio' (Rep. V, 479a5-6; Fédon 75d1) são avaliativos e boa parte de seus usos na linguagem ordinária está associada aos mais variados critérios subjetivos de aplicação (ver

um dado x é grande sempre em uma dada classe de objetos, em que x é maior que a maioria ou a média dos objetos desta classe.

${ }^{9}$ Para outra leitura, ver Castañeda (1972). 
Allen 1961, p. 327). Nem é preciso dizer o quanto é espinhosa a empreitada de livrar predicados como 'justo', 'injusto' (Rep. V, 479a6-7; Fédon 75d1), 'pio' e 'ímpio' (Rep. V, 479a7) de abordagens relativistas, segundo as quais seus usos estão inextricavelmente vinculados a uma ou outra comunidade de valores. Como se sabe, o próprio Platão engajou-se nesta árdua tarefa, sem deixar de reconhecer repetidas vezes o caráter controverso de matérias morais (Eutifron 7b2-d6; Alcibiades 111c-112a; Fédro 203a2-b2). Não é difícil, pois, conjecturar porque o filósofo entendeu que o uso ordinário destes termos está condicionado às mais diversas especificações contextuais, o que supostamente ensejaria nossa anuência à tese da CO.

Os exemplos de Platão nos levam a supor que um item sensível x sofre a CO na medida em que nenhuma propriedade F pode ser lhe atribuída sem a devida qualificação contextual, de tal sorte que a presença da propriedade oposta não-F em x poderia ser atestada tão logo o contexto de atribuição fosse alterado convenientemente. Por outro lado, a postulação de um F 'em si mesmo' parece consistir no reconhecimento de uma instância perfeita ou paradigmática do predicado F (Eutifron 6e3-6; Parmênides 132c12-d4; Rep. V, 472c4-5), à qual F se aplicaria sem qualificações e que, portanto, não seria suscetível à presença do predicado oposto (ver Annas 1981, p. 207). A Forma é dita 'em si mesma' por ser sujeito de um predicado que lhe pertence de maneira não-relacional, nãoatributiva, não-contextual (ver Kirwan 1974, p.113).

\section{O intérprete de República V em apuros: duas razões para rejeitar o argumento de 478e 7-480a4}

Com algum esforço, portanto, podemos perceber que os exemplos de atributos fornecidos em favor da tese da CO constituem um grupo coeso por apresentarem algum tipo de dependência contextual. Porém, se o quadro desenhado na seção anterior bastasse para caracterizar o contraste entre as Formas e os objetos sensíveis, o argumento de Platão contra o amante dos sentidos não prosperaria por duas simples razões.

A primeira delas reside em uma suposta generalização da $\mathrm{CO}$ para predicados que classificaríamos como gramatical e logicamente completos. É o caso dos termos hoje denominados 'individuativos', caracterizados pelo o que é conhecido, desde Quine (1960, pp. 90-95), como 'referência dividida'. Trata-se 
de expressões cujo sentido fornece um critério de individuação e um princípio de contagem para os objetos aos quais se aplicam, por meio do qual estes podem ser distinguidos enquanto itens discretos. O próprio Platão parece ter reconhecido que predicados unários e essenciais como 'dedo', 'pedra' e 'lenho' estão vinculados de tal forma à natureza do objeto ao qual se atribuem que não dão margem à presença de seu oposto (ver Rep. VII, 523c3-524a4; Alcibiades 1, 111b-112a1). Por isso, alguns intérpretes chegaram a concluir que, nos diálogos médios, a existência das Formas foi proposta apenas para predicados incompletos, enquanto os demais atributos seriam contemplados apenas nos diálogos tardios (ver Owen 1957, p.109; Allen 1961, p. 329; Irwin 1977, p. 7; Annas 1981, p. 209; Nehamas 1999, p. 77). ${ }^{10}$ Não obstante, o argumento platônico em Rep. V depende desta generalização. Se predicados completos não admitissem a copresença de seu oposto, sua instanciação em objetos particulares poderia muito bem ser conhecida pelo amante dos sentidos (cf. Brentlinger 1972, p. 62). ${ }^{11} \mathrm{~A}$ necessidade de negar ao amante dos sentidos a possibilidade de adquirir conhecimento em qualquer nível explicaria porque Platão, em 479a8, parece generalizar seu argumento e defender que cada um dos Fs sensíveis não é mais $\mathrm{F}$ do que não-F para qualquer valor de F. Como Platão parece ter reconhecido a distinção entre predicados completos e incompletos, há quem prefira entender as ocorrências do verbo ' $\varphi \alpha i v \varepsilon \sigma \theta \alpha \iota$ ' em seu sentido não-verídico, como se sua presença tivesse por fim justamente enfraquecer a tese platônica e autorizar assim a generalização (ver Kirwan 1973, pp. 117-119). Assumir-se-ia, no entanto, o risco de o argumento não provar o que deveria provar, já que nenhuma de suas premissas nos autoriza a inferir o estatuto metafísico

${ }^{10}$ Embora amplamente aceita, esta interpretação parece contradizer Rep. IX, 596a5-c1. Ademais, Platão reconhece uma forma para abelhas em Mênon 72b1-5 e teares em Crátilo 395b1-3 - apesar de ser possível alegar que as assim chamadas Formas platônicas, presentes nos diálogos médios, ainda não estejam em questão nestes dois diálogos.

${ }^{11}$ Annas (1981, pp. 210-212) defende que o domínio do conhecimento não se restringe às Formas, alegando que é possível conhecer a ocorrência de predicados individuativos no mundo sensível, para os quais o princípio da $\mathrm{CO}$ não é válido. Embora procure incluir os sensíveis no escopo do conhecimento, esta interpretação faria com que o argumento de Platão fosse incapaz de negar que seu adversário pudesse adquirir conhecimento. Inclusive, o conhecimento que o verdadeiro filósofo teria dos sensíveis seria idêntico ao do amante dos sentidos.

Manuscrito - Rev. Int. Fil., Campinas, v. 38, n.3, pp. 81-110, set.-dez. 2015. 
intermediário dos sensíveis a partir da mera ocorrência de aparências conflitantes (ver Kirwan 1973, p. 119).

Há ainda uma outra razão para julgarmos improcedente o argumento de 478e7-480a4. O próprio Platão reconheceu que predicados opostos jamais ocorrem a um mesmo sujeito quanto ao mesmo aspecto, com relação à mesma coisa ou ao mesmo tempo (Rep. IV, 436b9-d2). Com efeito, se um item sensível x pudesse ser $\mathrm{F}$ e não-F segundo as mesmas variáveis circunstanciais - por exemplo, se Símias pudesse ser simultaneamente mais alto e mais baixo do que Sócrates -, Platão poderia demonstrar a existência de uma insegurança epistêmica fatal ao seu adversário. Entretanto, a única característica dos exemplos fornecidos por Platão que bem ou mal corrobora a tese da CO é precisamente a pressuposição de qualificações que, uma vez alteradas, possibilitam a ocorrência dos predicados opostos. Portanto, pouco importa se cláusulas contextuais estão envolvidas nas aplicações de predicados incompletos a objetos sensíveis. Afinal, contanto que estas cláusulas sejam observadas e explicitadas, insegurança de nenhum tipo parece emergir da recusa da ontologia das Formas, restando assegurada ao amante dos sentidos a possibilidade de conhecer.

Portanto, qualquer intérprete que pretenda atribuir algum sucesso ao argumento de 478e 7-480a 4 deve fornecer respostas a estas duas dificuldades formuladas acima. A seguir, na seção III, lidaremos com a primeira delas.

\section{A generalização da copresença de opostos: o empirismo reducionista do amante dos sentidos}

Seria improdutivo buscarmos nos livrar destas dificuldades sem caracterizarmos com precisão os propósitos e pressupostos da argumentação platônica em 478e7-480a4. Em primeiro lugar, não há razão para crer que Platão tenha pretendido provar ali a existência das Formas, como pensam alguns (ver Allen 1961, p. 326/328; Shields 2003, pp. 71-74). O primeiro argumento contra o amante dos sentidos em Rep. V, 475e6-476e4, já acolhe uma ontologia tipicamente platônica sem se preocupar com o assentimento ou não de seu adversário. Em 476d7-e2, porém, Platão reconhece a necessidade de se elaborar um raciocínio que seja capaz de persuadir seu adversário sem depender da teoria das Formas, já que esta é posta em xeque pelo mesmo. Com efeito, não é preciso supor que nossa premissa (3) deva ter lugar cativo na estrutura teórica da 
metafísica platônica. Platão indica que o estatuto intermediário dos sensíveis não é exatamente um elemento desta estrutura, mas antes um recurso peirástico. Trata-se, nas suas palavras, de um 'consolo' (476e1), ou seja, uma concessão ao amante dos sentidos (ver Gosling 1960, pp. 118-119). Por isso, nada nos autoriza a imputar ao filósofo um comprometimento propositivo ou sistemático com a tese da $\mathrm{CO}$, menos ainda com a estranha opinião de que os sensíveis devem ser descritos como "entidades contraditórias" (Ross 1951, p. 38; cf. Allen 1961, pp. 326-327; Irwin 1999, p. 155). Por conseguinte, o problema da generalização da

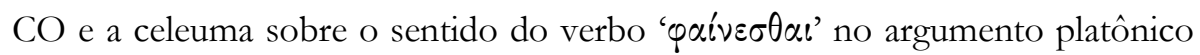
devem ser abordados segundo um arcabouço conceitual que não é o de Platão, mas o de seu adversário.

O amante dos sentidos apega-se a belos sons, cores e feições, mas é incapaz de captar o belo em si mesmo (476b4-7). Ele adota a posição reducionista segundo a qual a beleza de Helena de Tróia, por exemplo, não passa de um conjunto de propriedades sensíveis (feições, cores, sons) que, uma vez apreciadas em outro padrão de comparação, passarão a instanciar, igualmente bem, o atributo da fealdade (ver Hípias Maior, 289b1-7). Para Platão, itens sensíveis x, y, z (...) só são $\mathrm{F}$ na medida em que se assemelham a uma instância paradigmática de F (o F em si), passível somente de contemplação intelectual. Já segundo seu adversário, para que x, y e z (...) sejam ditos Fs, basta que sejam percebidos, por meio dos sentidos, enquanto tais. Como os sensíveis estão submetidos às mais diversas variações circunstanciais, nenhum deles é mais $\mathrm{F}$ do que não-F (479b89), o que leva o amante dos sentidos a negar possibilidade de qualquer instanciação ideal. Poderíamos acusá-lo de assumir a conflituosa posição de reconhecer a existência dos 'semelhantes' rejeitando o paradigma ao qual se assemelham (476c1-5). Contudo, reconhece Platão, isso significaria argumentar contra um adversário impondo-lhe a existência de entidades que ele não está disposto a aceitar (476d7-e2). ${ }^{12}$ Com um universo limitado aos objetos e

12 Comparar este princípio à "condition of noncontroversiality" e o "dialectical requirement" em Fine (2003b) e Fine (2003c) respectivamente. Uma diferença crucial que a interpretação que propomos apresenta em relação à proposta de Fine consiste em assumir que as premissas (2) e (3) não são exatamente incontroversas para o amante do sentidos, mas sim resultam necessariamente de seu empirismo reducionista. A metafísica platônica, ao contrário, não precisa se comprometer com (2) e (3) justamente por assumir a teoria das Formas - ou assim argumentaremos.

Manuscrito - Rev. Int. Fil., Campinas, v. 38, n.3, pp. 81-110, set.-dez. 2015. 
propriedades sensíveis, o amante dos sentidos faz da percepção o veículo do conhecimento em um sentido radical, se apegando aos dados sensoriais como suficientes para aferir o valor de verdade de qualquer conteúdo proposicional. É preciso enfrentá-lo em seu próprio terreno, em que apelar à teoria das Formas não possui nenhum valor argumentativo.

Como se sabe, a equação entre percepção e conhecimento é submetida a rigoroso exame na primeira parte do diálogo Teeteto. Em 151d7-e3, Teeteto define conhecimento como percepção sensível ( $\left.\alpha \imath^{\prime} \sigma \theta \eta \sigma \iota \varsigma\right)$. Um enunciado não pode ser considerado definicional sem que o definiens e definiendum sejam coextensivos, o que significa, neste caso, que a percepção tem de ser condição necessária e suficiente para o conhecimento (ver Burnyeat 1990, pp. 10-11). Prontamente, a definição de Teeteto é desafiada pela trivial constatação de que os sentidos proporcionam experiências conflitantes que ensejam, por sua vez, juízos incompatíveis entre si. ${ }^{13}$ Por exemplo, quando sopra uma mesma corrente de ar, ocorre por vezes que um de nós sente frio, enquanto o outro não (152b 24). Sócrates, então, mobiliza em socorro de Teeteto uma epistemologia relativista, atribuída por ele a Protágoras (151e 8ss.). A fórmula protagórica segundo a qual 'o homem é medida de todas as coisas' é interpretada como significando que nenhum objeto possui qualquer propriedade independentemente de um sujeito

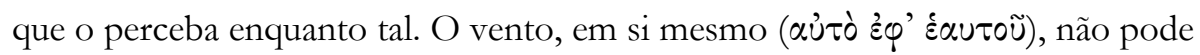
ser dito nem frio nem quente, mas é frio para aquele que sente frio e não é frio para

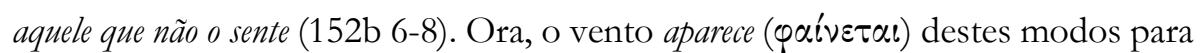
cada um dos sujeitos percipientes, mas aparecer, acrescenta Sócrates, nada mais é do que ser percebido (152b 10-12). Ambos concluem ser provável, afinal de contas, que as coisas sejam, para cada um, tal como ele as percebe (152c 2-3).

Esta passagem revela como pode ser enganosa a discussão sobre o

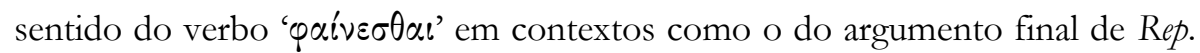
V. Somos tentados a distinguir a copresença de opostos, por um lado, e a ocorrência de aparências conflitantes, por outro, como fenômenos distintos e não relacionados, associados a duas interpretações antagonistas (uma ontológica e outra epistêmica) de nossa premissa (2), formulada em 479a5-b3. No entanto,

${ }^{13}$ Nesta primeira etapa do diálogo, pressupõe-se que a percepção já contenha em si alguma capacidade judicativa. Ver Bostock (1988 pp. 41-43) e Burnyeat (1990, p. 11). 
em um contexto argumentativo em que a percepção é entendida como uma faculdade capaz de engendrar por si só conhecimento, a concorrência de aparências conflitantes acarreta a copresença de propriedades opostas. Este parece ser o caso de Teeteto, 152b6-c6. Se, por exemplo,

(i) $\mathrm{x}$ aparece como F para um sujeito $a$

então, por 152b 12,

(ii) a percebe que x é F.

Em um contexto em que percepção é condição suficiente para conhecimento, temos que

(iii) $a$ sabe que x é $\mathrm{F}$.

Como o conhecimento implica a verdade do conteúdo proposicional sobre o qual incide, de (iii), se segue:

(iv) x é F.

Se aplicarmos o mesmo raciocínio ao enunciado

(i’) $\mathrm{x}$ aparece como não-F para um sujeito $b$

seríamos levados a concluir:

(iv’) x é não-F.

Certamente, em (i) e (i'), o verbo 'aparece' ( $\varphi \alpha$ ' $v \varepsilon \sigma \theta \alpha \imath$ ) ocorre em um sentido verídico, já que implica a verdade de 'x é F' e 'x é não-F'. Caso contrário, (iv) e (iv') não se seguiriam de (i)-(iii) e (i')-(iii') respectivamente, nem seria possível concluir, em favor da definição de Teeteto, que a percepção "é sempre 
daquilo que é o caso e sempre inequívoca" (152c5-6). ${ }^{14}$ Não obstante, este uso do verbo não perde seu vínculo com a noção de manifestação ou aparição, a qual envolve a presença de um sujeito percipiente. Portanto, neste quadro teórico, não há oposição entre x 'parecer ser F' e 'ser F', já que a existência de um sujeito $a$ que o percebe como $\mathrm{F}$ e para o qual $\mathrm{x}$ parece $\mathrm{F}$ é precisamente aquilo que faz de $\mathrm{x}$

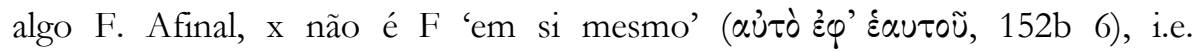
independentemente de um sujeito que o perceba como F. Assim como Teeteto na defesa de sua primeira definição de conhecimento, o amante dos sentidos de Rep. V tem à sua disposição a possibilidade de acolher uma epistemologia relativista, de vocação protagórica, para garantir a objetividade de seus estados cognitivos. Esta aproximação nos faz crer que as discussões sobre o sentido do

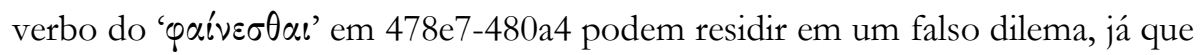
suas ocorrências devem ser entendidas em seu sentido verídico mesmo que ali esteja implicada a apreensão de propriedades sensíveis por sujeitos de percepção.

A exploração deste esquema conceitual na sequência do Teeteto, 154c1$155 \mathrm{c} 7$, nos fornece elementos para abordar o problema da generalização da CO.

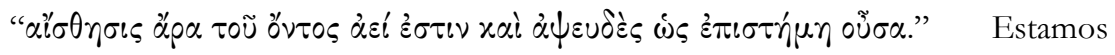

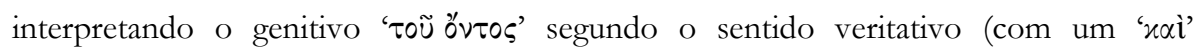
epexegético), ainda que este passo não seja estritamente necessário para os nossos presentes propósitos. Uma boa razão para entender o particípio neste sentido é evitar uma tensão no texto platônico. Neste trecho do diálogo, Sócrates está lançando mão da fórmula protagórica segundo a qual 'o homem é a medida de todas as coisas' para fundamentar a definição do conhecimento como percepção proposta por Teeteto (151e 8ss.). Na epistemologia relativista de Protágoras, o homem é a medida "das coisas que são, de que são, e das que não são, de que não são" (152a2-4). Tudo indica que este uso do verbo 'ser' é copulativo (152b1-8). Associada à primeira definição de Teeteto, esta fórmula nos diria que, quando percebemos 'aquilo que é' (um x que é F), sabemos 'que é' (que x é F), e quando percebemos 'aquilo que não é' (um x que não é F), sabemos 'que não é' (que x não é F). Por um lado, esta tese implica que a percepção pode ser tanto 'daquilo que é' (de um x que é F) como 'daquilo que não é' (de um x que não é F) apenas com respeito ao sentido copulativo do verbo 'ser' - o que estaria em conflito com um

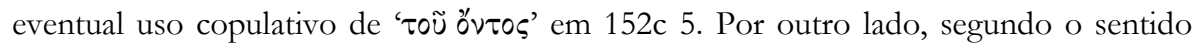
veritativo, a percepção seria somente 'daquilo que é' (daquilo 'que é verdadeiro' ou 'que é o caso'), já que, segundo a teoria ali proposta, haveria sempre correspondência entre o conteúdo judicativo produzido pela percepção e o fato predicativo por ela apreendido.

Manuscrito - Rev. Int. Fil., Campinas, v. 38, n.3, pp. 81-110, set.-dez. 2015. 
Um aparente descuido com o comportamento semântico dos predicados incompletos, análogo ao que alguns atribuem a Platão em Rep. V, parece ter levado o filósofo a concluir que as três seguintes sentenças seriam inconsistentes entre si (155b5-6):

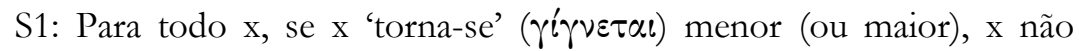
permanece igual si mesmo (155a2-5).

S2: Para todo $\mathrm{x}$, se $\mathrm{x}$ não sofre acréscimo ou diminuição, $\mathrm{x}$ permanece igual a si mesmo (155b1-3).

S3: Para todo x, se x é F no contexto $c_{1}$ e passa a ser não-F no contexto

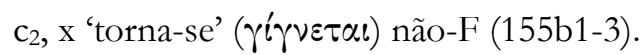

Platão lança mão de dois exemplos em que os antecedentes de S1 e S2 são conjuntamente satisfeitos. Como seus conseqüentes são contraditórios entre si, o filósofo (supostamente) pretendeu ter mostrado que S1 e S2 não podem ser simultaneamente verdadeiras. No primeiro deles, três conjuntos de dados são comparados. Embora uma quantidade de seis dados seja maior (F) quando comparada a um conjunto de quatro dados, ela 'torna-se' ( $\gamma$ ' $\gamma \nu \varepsilon \tau \alpha \iota)$ menor (nãoF) quando comparada a um conjunto de doze (154c1-5), como previsto na sentença S3. Por 'tornar-se' menor na passagem de um instante a outro, a quantidade de seis dados satisfaria o antecedente de S1. Por outro lado, por se tratar da mesma quantidade de (seis) dados, o antecedente de S2 também seria satisfeito, do que resultaria que o conjunto de seis dados permanece e não permanece igual a si mesmo. No segundo exemplo, Platão considera uma situação em que Sócrates, hoje maior do que Teeteto, passa a ser menor na medida em que o jovem cresce, sem que o próprio Sócrates altere em nada sua altura. Novamente, como seus respectivos antecedentes seriam satisfeitos e seus consequentes são contraditórios, S1 e S2 seriam incompatíveis entre si. Logo notamos que este raciocínio é falacioso. 'Menor' e 'maior' são predicados relacionais, o que requer a explicitação do segundo membro da comparação em S1 e S3. Com efeito, S1 altera seu valor de verdade dependendo de como for complementada: se ' $\mathrm{x}$ torna-se menor' significa que $\mathrm{x}$ torna-se menor do que $\mathrm{o}$ próprio x era no passado, a implicação é verdadeira; se, no entanto, afirma-se que 
$\mathrm{x}$ torna-se menor do que $\mathrm{y}$, em que $\mathrm{x} \neq \mathrm{y}$, a proposição é falsa. É fácil perceber porque afinal esta passagem serviu de munição para aqueles que acusaram Platão de não ter se dado conta do caráter incompleto de predicados como 'menor' e 'maior' (ver Kirwan 1974, p. 128).

Contudo, tal leitura não faz justiça ao filósofo. Longe de revelar uma ignorância do funcionamento de predicados incompletos, o raciocínio de Platão na passagem tem como propósito justamente indicar em que tipo de impasses nos enredamos quando deixamos de tratar predicados relacionais como tais. Caracterizada deste modo, a passagem estaria em perfeita conformidade com o contexto em que os exemplos são formulados, no qual Sócrates, exercendo sua arte maiêutica, busca fornecer à definição de Teeteto seus melhores fundamentos epistemológicos e ontológicos. A ocorrência de aparências conflitantes não ameaça a definição de conhecimento como percepção precisamente porque, uma vez aceito o relativismo protagórico, todos os predicados que significam propriedades sensíveis devem ser analisados como semanticamente incompletos e, portanto, como dependentes do contexto de atribuição. $\mathrm{O}$ argumento em 154c1-155c7 nos mostra que não atentar para o estatuto relacional dos predicados 'maior' e 'menor' leva à produção de antinomias. Do mesmo modo, a atribuição dos predicados 'quente' e 'frio' a um mesmo vento só se mostrará inconsistente (e, portanto, ameaçará a definição de Teeteto) se negligenciarmos que o vento não é frio ou quente 'em si mesmo' (i.e. de modo não-relacional), mas sim em relação a sujeitos que o percebem destes modos. Sabemos que as sentenças 'Símias é maior' e 'Símias é menor' não são necessariamente inconsistentes, pois certamente não há inconsistência entre as sentenças 'Símias é maior do que Sócrates' e 'Símias é menor do que Fédon', em que o segundo argumento da relação 'ser maior (menor) que' encontra-se explicitado. Semelhantemente, alerta-nos Platão, 'o vento é frio' e 'o vento é quente' não são necessariamente inconsistentes entre si. Com as devidas cláusulas relacionais, teríamos 'o vento é frio para Sócrates' e 'o vento é quente para Teeteto', sentenças que já não ameaçam a objetividade dos juízos produzidos pela percepção na medida em que a atribuição das propriedades em questão é acompanhada de uma menção aos sujeitos que as apreendem por meio dos sentidos.

Portanto, assim como a explicitação do segundo membro da comparação evita o paradoxo dos dados em 154c1-5, a explicitação do sujeito percipiente evita que aparências conflitantes levem à formulação de juízos incompatíveis. Agora, enfim, estamos em condições de compreender a 
generalização do fenômeno da $\mathrm{CO}$ da qual depende o sucesso do argumento final de Rep. V. Para o amante dos sentidos, todos os juízos ou possuem diretamente um conteúdo perceptivo ou devem ser analisados nos termos de juízos mais básicos em que só há a ocorrência de propriedades sensoriais. Deste modo, uma proposição com um predicado unário e individuativo como 'Sócrates é homem' só pode ter seu valor de verdade decidido na medida em que for reduzida a proposições mais fundamentais em que se constate a ocorrência do conjunto de características sensíveis (forma, cores, ruídos) que associamos ao predicado 'homem'. Portanto, o fato (reconhecido pelo próprio Platão) de que raramente há controvérsia sobre a aplicação de termos como 'homem', 'dedo' ou 'lenho' não impede que estes predicados sejam tratados como incompletos pelo amante dos sentidos; afinal, segundo seu empirismo reducionista, proposições com predicados individuativos são reduzidas a proposições mais básicas que envolvem exclusivamente atributos sensíveis, cuja verdade depende de um sujeito percipiente que os apreenda.

No diálogo Teeteto, esta epistemologia relativista é vinculada a uma doutrina 'secreta' (152c 8-11), associada não só a Protágoras, mas a Heráclito, Empédocles e os poetas Epicarmo e Homero (152d 2-e6). Trata-se de uma teoria metafísica segundo a qual nada propriamente 'é', mas tudo 'vem a ser' (152e1), visto que todas as coisas se originam do fluxo e da mudança (152e8). Também o amante dos sentidos em Rep. V parece ser descrito como um partidário desta ontologia fluxista, alguém que não crê em uma instância ideal do belo que permaneça sempre a mesma e do mesmo modo, mas somente nas várias coisas belas (479a1-3) que se mostram, afinal de contas, ora belas, ora feias (479a5-6). É de se esperar que a mencionada epistemologia relativista esteja aliada a uma metafísica deste tipo. Se um x qualquer só pode ser F na medida em que um sujeito $a$ o percebe como $\mathrm{F}$ e se a relação entre x e $a$ é acidental e fortuita, seguese que x não 'é' propriamente F, mas 'vem a ser' F ao entrar em contato com o sujeito percipiente $a .{ }^{15}$ Neste quadro, nenhuma propriedade está propriamente no item percebido ou no sujeito percipiente, mas surge como algo intermediário a partir da interação de ambos (153d8-154a4). É importante notar que, para a epistemologia protagoriana, esta consequência se mantém seja $\mathrm{F}$ um atributo que usualmente entendemos como captando a essência ou natureza do objeto ao qual

15 Burnyeat (1990, p. 18) afirma: "the Heraclitean story [...] is a metaphysical projection of the world in which the Protagorean relativism holds good".

Manuscrito - Rev. Int. Fil., Campinas, v. 38, n.3, pp. 81-110, set.-dez. 2015. 
se aplica, seja $\mathrm{F}$ não mais que um atributo acidental do objeto em questão. ${ }^{16}$ Portanto, o próprio filósofo nos fornece os elementos para elaborar a útil hipótese exegética de que o esquema conceitual do amante dos sentidos, tanto em sua epistemologia relativista quanto em sua ontologia fluxista, inclui não só predicados relacionais e atributivos, mas também propriedades que outrora classificaríamos como individuativas e essenciais. ${ }^{17,18}$ Desta maneira, desde que o argumento final de Rep. V seja interpretado como operando um arcabouço teórico que não é o de Platão, mas o de seu adversário, não há impedimentos para que o fenômeno da CO seja generalizado.

\section{Explicação pelas Formas e univocidade conceitual}

Abordado o problema da generalização da CO, resta-nos lidar com a segunda dificuldade mencionada ao final de nossa seção II. Se o conhecimento se limitar aos objetos particulares e suas propriedades sensíveis, como pensa o amante dos sentidos, todo predicado seria semanticamente incompleto,

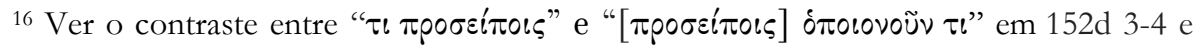
entre " $\pi \alpha ́ \nu \tau \alpha "$ e " $\pi \alpha \nu \tau o \check{\alpha}$ " em 157a1-2. Sobre esta distinção em 152d3-6, ver McDowell (1973) ad locum. Cf. Teeteto, 157a 1-2.

${ }^{17} \mathrm{~A}$ rigor, esta distinção é aqui superada. A única diferença que permanece entre as duas classes de termos é o fato dos relacionais ou atributivos se caracterizarem por um duplo grau de incompletude. O primeiro se deve ao próprio funcionamento lógico do predicado, como quando se faz necessária a ocorrência de $n$ argumentos para uma relação de aridade $n$, ou quando um adjetivo atributivo é acompanhado de um substantivo que qualifica seu uso, e.g. 'x é maior que y', 'x é um animal grande'. O segundo grau, comum também aos predicados individuativos, diz respeito a um sujeito percipiente que apreende a propriedade em questão, e.g. 'x é maior que y para um sujeito percipiente $a$ ' ou 'x é um dedo (ou x possui a forma e a textura, etc., de um dedo) para um sujeito percipiente $a$ '.

18 Irwin (1977) argumenta que o próprio Platão teria adotado uma ontologia fluxista para os objetos sensíveis, mas que o conceito de fluxo em questão se limitaria à noção de "mudança aspectual" (id. ibid., p. 4), que exclui predicados individuativos. Como a teoria que ora descrevemos é adotada apenas pelo amante dos sentidos, nossa proposta não impede que uma ontologia fluxista de caráter aspectual seja imputada a Platão, como quer Irwin. 
caracterizando-se pela pressuposição direta ou indireta de cláusulas contextuais que, uma vez alteradas convenientemente, ocasionariam a ocorrência de seu oposto. Contudo, se entendido deste modo, o fenômeno da CO não produz juízos contraditórios desde que as cláusulas contextuais pertinentes estejam devidamente explicitadas. Embora as sentenças 'o vento é frio' e 'o vento é quente’ pareçam significar proposições contraditórias, o mesmo não ocorre com suas respectivas versões complementadas: 'o vento é frio para Sócrates' e 'o vento é quente para Teeteto'.

Portanto, tratar todos os predicados como semanticamente incompletos é precisamente o que garante, em uma matriz epistemológica relativista, a objetividade dos estados cognitivos do amante dos sentidos. O tipo de inconsistência sistêmica que Platão pretende lhe atribuir só emergirá se for possível mostrar que seu adversário não possui as ferramentas para conhecer efetivamente se, com respeito às mesmas variantes circunstanciais, um dado x possui um predicado F e não o seu oposto. Neste caso, a tese da CO, promovida pela premissa (3), precisaria significar que um x sensível qualquer é indiferentemente $\mathrm{F} \mathrm{e}$

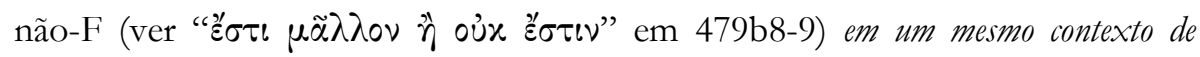
atribuição.

Temos afirmado que a CO, formulada nestes termos, não é propriamente um elemento da ontologia platônica, mas algo que resulta da recusa das Formas e que, portanto, pode ser atribuído ao amante dos sentidos. É imprescindível ter em conta, contudo, que esta interpretação não é incompatível com o incontestável fato de que, para Platão, dois predicados opostos podem se atribuir ambos a um mesmo objeto sensível (ainda que não a uma mesma Forma) em contextos distintos de atribuição. Em uma conhecida passagem no Fédon, Platão argumenta que os sensíveis podem, em contextos diversos, apresentar tanto o predicado 'igual' quanto 'desigual', o que não vale para o 'Igual em si', cujas propriedades são insensíveis a variações contextuais (74b4-c10). Este raciocínio lhe permite concluir uma tese fundamental de sua metafísica, segundo a qual o 'Igual em si', assim como as demais Formas, não se reduz a nenhum objeto ou classe de objetos particulares.

Passagens como Fédon 74b4-c10 exprimem o esforço de Platão em combater qualquer tentativa de reduzir as Formas a tipos mais familiares de entes (ver Shields 2003, pp. 70-71). Neste caso, trata-se de objetos particulares. Em outras passagens, porém, o que está em questão é a oposição entre Formas e 


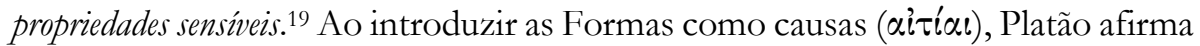
que, se houver algo belo para além do 'Belo em si', este será belo somente na

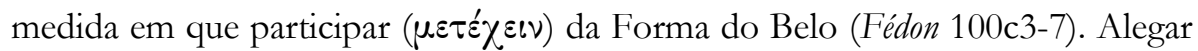
que algo é belo porque tem uma certa cor ou um certo formato não possui as credenciais de uma boa explicação (Fédon 100c10-d2). Portanto, Platão contrasta Formas e propriedades sensíveis em um registro explanatório, recorrendo uma vez mais à ocorrência de predicados opostos em contextos distintos. ${ }^{20}$ Falhamos em explicar de maneira apropriada sempre que nos limitamos a dizer que um dado x é $F$ porque possui uma dada propriedade sensível $G$, pois $G$ pode explicar ora uma ocorrência de F, ora uma ocorrência de não-F. Um homem com 1,75m de altura dificilmente seria considerado baixo para um jóquei, embora certamente não se contaria entre os mais altos caso fosse um jogador de basquete (cf. Fédon 96d7-e4). Pelas mesmas razões, exemplifica Shields (2003, p.71), a dissonância pode embelezar um concerto de Bartok, ainda que não seja bem-vinda em um concerto de Bach.

A primazia explanatória das Formas em relação às propriedades sensíveis é parte crucial da epistemologia de Platão. É sabido que um dos traços inalienáveis do conhecimento para o filósofo é não apenas a verdade do conteúdo proposicional em questão (o que caracterizaria somente opinião verdadeira), mas o provimento de uma explicação apropriada para o fato constatado (ver Mênon 98a2-3; Teeteto 201c8-d1). Seria certamente imprudente negligenciar este requisito em nossa leitura de Rep. V. A discussão sobre predicados opostos em contextos

19 Gosling (1960) argumentou que, em Rep. V, a expressão ' $\tau \dot{\alpha} \pi \circ \lambda \lambda \grave{\alpha}$ ' se refere a propriedades sensíveis, não a instâncias particulares. Ver, na mesma linha, Murphy (1951, pp. 110-111), Irwin (1977), Irwin (1999), Fine (2003b) e Fine (2003c). Para uma reposta aos argumentos de Gosling, ver White (1978). Ainda que por vezes reconheça a copresença de opostos em propriedades, Platão explicitamente a atribui a instâncias particulares, como em Hipias Maior 289b2 (em que uma garota bela é dita igualmente feia) ou em Fédon 102b4-6 (em que se diz que tanto a grandeza quanto a pequenez se encontram em Símias). Essa parece razão suficiente para não nos limitarmos a um caso em detrimento de outro, o que nos leva a preferir a neutralidade neste debate.

${ }^{20}$ Como notaram diversos intérpretes, dentre os quais, Gosling (1960, p. 123); Irwin (1977, pp. 7-9); Irwin (1999, p. 159-161); Fine (2003b, p. 80); Fine (2003c, p. 93); Shields (2003, p. 71).

Manuscrito - Rev. Int. Fil., Campinas, v. 38, n.3, pp. 81-110, set.-dez. 2015. 
em que a noção de explicação está em foco nos fornece ao menos um dos critérios platônicos para adequação explanatória: uma propriedade $G$ falha em explicar porque um certo x é $F$ sempre que houver um y que seja $F$, mas não $G$, ou que seja G, mas não F (ver Fédon 96e6-97b7; Irwin 1999, p. 159). ${ }^{21}$ Ter conhecimento de que x é $F$ envolve apreciar x segundo uma descrição $G$ que mantém com $\mathrm{F}$ uma relação estável de conexão explanatória. Este ponto é caro também a Aristóteles, para o qual não é possível ter conhecimento, por exemplo, de que uma dada figura isósceles tem a soma dos ângulos internos igual a dois ângulos retos sem saber que é por ser triângulo (e não por ser isósceles) que ela apresenta esta propriedade (ver Segundos Analíticos I 4 73b32-74a3; I 5, 74a16-b4; I 24, 85b4-15; 85b23-27; 85b38-86a3).22 Algo pode ter a soma de seus ângulos internos igual à soma de dois retos sem ser isósceles, mas não sem ser triângulo. Por isso, apenas o tipo universal triângulo possui este atributo 'em si mesmo' ( $\kappa \propto \theta$ '

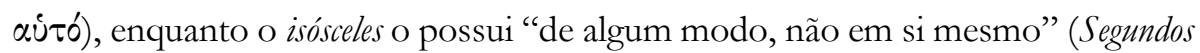
Analíticos I 4, 74a1-3). Semelhantemente, para Platão, julgar que um objeto x é F por apresentar uma propriedade sensível $G$ significa não estar familiarizado com $o$ tipo relevante em virtude do qual x é $\mathrm{F}$ e com o qual $\mathrm{x}$ mantém a relação de participação, a saber, o F 'em si'. ${ }^{23}$ Portanto, a independência contextual que Platão exprime pela fórmula 'o F em si' deve ser estendida à primazia explanatória das Formas em relação às propriedades sensíveis, já que estas últimas mantêm com o fato investigado uma conexão frágil o bastante para serem consideradas incapazes de fundamentar, por si só, conhecimento autêntico.

Contudo, ainda é custoso crer que o verdadeiro filósofo (platônico) esteja de fato em posição vantajosa em relação ao amante dos sentidos. A afirmação de que um dado x é F porque participa da Forma de F parece vaga o suficiente para não ser considerada uma boa explicação. $O$ jargão da participação parece apenas reduzir a atribuição de uma propriedade a um objeto a uma relação

\footnotetext{
${ }^{21}$ Notar que esta fórmula vale quando $\mathrm{x}=\mathrm{y}$, desde que as respectivas predicações sejam confrontadas em contextos distintos.

22 Para uma meticulosa análise desta tese em Aristóteles, ver Angioni (2007). Ver também meu Zuppolini (2014, pp.16-17).

${ }^{23}$ Para uma breve aproximação, similar à que propomos aqui, entre Platão e Aristóteles, ver Irwin (1999, p.159)
} 
entre dois objetos, um concreto e outro abstrato. Ademais, a presença de um atributo $\mathrm{F}$ em qualquer sujeito que não seja o F 'em si' permanece sensível a alterações contextuais, enquanto a explicação abstrata pela Forma parece justamente negligenciar as cláusulas contextuais que o próprio Platão julga indispensável explicitar quando se predica algo de itens sensíveis. Se, por um lado, os filósofos são os únicos capazes de conhecer de fato, por outro, temos a impressão de que seu conhecimento não tem valor algum para a constante interação com os entes familiares na qual nossa vida, em última instância, consiste. Com efeito, toda discussão sobre conhecimento em Rep. V tem como principal objetivo enfrentar a mais perigosa 'onda' crítica que ameaça o projeto platônico de Estado ideal (472a-7), a qual censura a sua orientação segundo a qual os filósofos devem governar. Mas como estes poderiam elaborar leis, administrar crises, julgar cidadãos e aplicar-lhes penas se o conhecimento que os credencia ao poder não passasse de uma coleção de explicações abstratas e alheias aos fatores que operam no mundo sensível (ver Annas 1981, p. 194)?

Como já foi notado na literatura, a fórmula ' $\mathrm{x}$ é $\mathrm{F}$ porque participa da Forma de F', proposta em Fédon 100c3-7, é mais um esquema explanatório geral - a ser suplementado, caso a caso, pelas especificações cabíveis - do que ela mesma uma explicação (ver Irwin 1999, p. 166). E temos razões para entendê-la como introduzindo um segundo requisito para adequação explanatória - e não propriamente uma explicação que atende este requisito: explicar porque x é $\mathrm{F}$ envolve, inter alia, mobilizar uma definição unívoca do que significa ser F (cf. Vlastos, 1973c, pp. 91-93). Os diálogos socráticos já estabelecem que buscar por uma definição de $\mathrm{F}$ consiste em determinar aquilo em virtude do que todos os Fs são F (Eutífron 6d9-e1; Mênon 72c6-d1). Ademais, o caráter definicional de uma explicação apropriada é marcado por certa unicidade. Em Mênon, o personagem homônimo tenta definir o que é virtude enumerando uma lista de casos, supondo que a definição deva variar dependendo do objeto ou classe de objetos considerada: a virtude para um homem consistiria em administrar assuntos de interesse público, de modo a beneficiar os amigos e prejudicar os inimigos, enquanto a da mulher consistiria em cuidar de assuntos domésticos e ser submissa ao marido, sendo distinta ainda a virtude de uma criança ou de um idoso, etc. (71e1-72a5). Platão não pode estar em completo desacordo com este procedimento. No livro I da República, o filósofo argumenta que cada ser vivo, órgão ou instrumento tem sua 'função' (है pyov) própria e que a virtude de cada coisa consiste na performance excelente desta função (352d9-353e11). Se 
homens e mulheres têm 'funções' distintas, é preciso, para julgar se Sócrates é virtuoso, ter à disposição uma definição do que vem a ser a virtude para os homens, o que envolve saber em que consiste a performance excelente da função própria do homem. Ao avaliarmos o caráter de Xantipa, por sua vez, o faremos por meio de uma definição da virtude característica das mulheres, e assim nos demais casos. Portanto, se toda aplicação de uma propriedade $\mathrm{F}$ a objetos particulares é sensível ao contexto, é preciso termos à nossa disposição, em cada caso, uma definição contextual de F que leve em conta um dado parâmetro de avaliação, um elemento (ou conjunto de elementos) de comparação, um universo de discurso determinado, entre outros fatores.

Não obstante, a correção de definições contextuais, para Platão, subordina-se sempre ao conteúdo de uma definição unívoca, sem a qual aquelas não passariam de delimitações arbitrárias do conceito definido. Na suposição de que estejam corretas, as definições casu ad casum de Mênon nos forneceriam critérios para elaborarmos uma lista de tipos de virtude. No entanto, sem uma definição unívoca, os elementos desta lista não guardariam nenhuma semelhança entre si além do fato de fazerem parte dela (ver Irwin 1999, p. 146). Espera-se que as virtudes do homem, da mulher e da criança apresentem algo em comum a partir de que são ditas 'virtudes', pois, caso contrário, a univocidade mesma do conceito estaria ameaçada. É este algo em comum que Platão descreve como "uma mesma e única forma que em razão da qual são virtudes" (Mênon 72c4-5). Portanto, ao defender a realidade de um F único para além dos muitos Fs a que temos acesso imediato no mundo sensível, Platão pretende afirmar não apenas a existência de uma instância paradigmática de $\mathrm{F}$, mas a disponibilidade de uma definição paradigmática de $\mathrm{F}$, à qual se subordinam todos os diversos critérios de aplicação que possam se impor em diferentes contextos (cf. Owen 1957, p.110).

Este quadro está em notável consonância com argumento de Rep. V. O amante dos sentidos é descrito como alguém que rejeita a existência de 'um belo

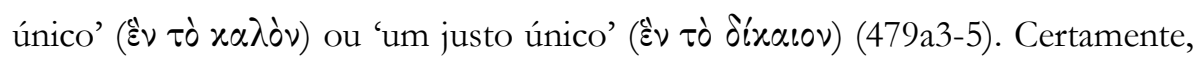
o adversário de Platão não está negando - e tampouco Platão está endossando a (talvez absurda) visão de que a beleza e a justiça e as demais propriedades possuem uma única instância, como se houvesse uma só coisa que pudesse ser dita 'bela', uma só que pudesse ser dita 'justa' e assim por diante. É mais plausível entender sua posição como negando a existência de um conceito unívoco, com 
uma definição que unifique seus subtipos e casos em um domínio coeso. ${ }^{24}$ Se não é possível definir sem limitações contextuais, o melhor que se pode conseguir é um enunciado que, uma vez alterado o contexto de atribuição, deixa de definir o conceito em questão, podendo inclusive explicar a ocorrência do conceito oposto. Como vimos, Platão não pode ser acusado de negligenciar o valor de definições contextuais. Possuí-las, porém, não é suficiente para se ter conhecimento. Conhecer, para Platão, envolve a capacidade de contar uma história causal relativamente completa, que vincule os dados concretos que a experiência nos proporciona e as condições de verdade que cada contexto nos impõe a uma definição abstrata que garanta a univocidade do conceito cuja ocorrência está sendo apreciada. Sem uma definição de virtude que atenda este requisito, não teríamos nenhum critério para afirmar que aquilo que entendemos como a 'virtude do homem' é, afinal de contas, uma virtude e não um vício. Com efeito, é no mínimo polêmico afirmar que seja virtuoso administrar os interesses públicos de modo a beneficiar os amigos e prejudicar os inimigos. Aliás, é provável que esta conduta passe a ser avaliada como viciosa tão logo se estabeleça uma definição unívoca de virtude que atenda as condições mais básicas de razoabilidade e que mantenha alguma conformidade com o uso ordinário deste conceito (ver República I, 334b7-335e6). Portanto, até que uma definição unívoca de virtude esteja determinada, a assim chamada 'virtude do homem' não é mais virtude do que vício (ver 479b8-9). Do mesmo modo, ainda que todas as variáveis circunstanciais estejam devidamente consideradas, Sócrates será indiferentemente virtuoso e vicioso até que se demonstre que ele 'participa' da Forma da virtude, i.e. que ele atende as condições providas por uma definição unívoca de virtude, da qual dependem quaisquer outras definições contextuais.

\footnotetext{
24 Preferimos atribuir univocidade a conceitos, e não termos, para evitarmos tratar de expressões ambíguas, que não estão em questão. Platão não está preocupado com o fato do termo 'banco' receber definições totalmente díspares quando falamos de um assento na praça ou de uma instituição financeira. Sua preocupação diz respeito a casos em que um mesmo conceito recebe diferentes definições dependendo do contexto em que é investigado.
} 


\section{Conclusão}

Pretendemos ter oferecido uma reconstrução do argumento apresentado em Rep. V, 478e 7-480a4, que tenha sido capaz de atingir dois propósitos centrais. Por um lado, buscamos garantir o sucesso do argumento a despeito dos inúmeros desconfortos que ele suscita em leitores mais exigentes. Por outro, procuramos evitar comprometer Platão com uma redução indesejável do escopo do conhecimento que excluísse os objetos e propriedades sensíveis do domínio do cognoscível.

Dentre os desconfortos mencionados, destaca-se aquele provocado pela estranha tese da Copresença de Opostos (CO), segundo a qual, para qualquer propriedade $\mathrm{F}$ que um item sensível $\mathrm{x}$ venha a possuir, $\mathrm{x}$ possuirá também a propriedade oposta não-F. Vimos que Platão a aceitaria sem problemas desde que as presenças de $\mathrm{F}$ e não-F em x ocorressem em contextos distintos de predicação. Não obstante, não é nestes termos que a premissa (3) do argumento deve ser interpretada. Se predicados opostos ocorressem a objetos sensíveis apenas em contextos distintos, bastaria que as especificações contextuais adequadas estivessem devidamente explicitadas para que o amante dos sentidos pudesse adquirir conhecimento. Portanto, a afirmação de que os Fs sensíveis participam tanto de F quanto de seu oposto não-F precisa significar que, em um mesmo contexto de predicação, nenhum deles é F com mais razão do que é não-F.

Ocorre que nada na filosofia de Platão o obriga a admitir esta nova versão da premissa (3). Porém, como estatuto intermediário dos sensíveis é descrito como um 'consolo' (476e1), uma concessão ao seu adversário, pudemos identificá-lo como um elemento do arcabouço teórico do amante dos sentidos e não de Platão. Nossa reconstituição deste arcabouço envolveu a consideração de passagens da primeira parte do diálogo Teeteto, em que a definição de conhecimento como percepção sensível é explorada. Razões historiográficas podem lançar dúvidas sobre a adequação desde procedimento exegético, visto que a maioria dos intérpretes data esta obra como posterior à composição da República. Não obstante, a caracterização do amante dos sentidos em Rep. V corrobora esta aproximação entre os dois diálogos. Ademais, foi esta reconstituição que nos forneceu os instrumentos para resolver uma série de outros desconfortos que o argumento de Rep. V suscita - como a inferência de (3) a partir de (2) (em que de uma afirmação sobre 'aparência' se segue uma sobre 'participação') ou a generalização do fenômeno da CO (em que predicados 
individuativos passam a ser analisados como semanticamente incompletos). A utilização do diálogo Teeteto na reconstrução do esquema conceitual do amante dos sentidos deve, portanto, ser recebida como hipótese exegética a ser avaliada segundo sua capacidade de solucionar, de maneira sistemática, o maior número possível de problemas de interpretação que a passagem em questão oferece.

Por fim, ao reconhecer a explicação (e sua configuração definicional) como um traço inalienável do conhecimento para Platão, pudemos compreender por que razão, uma vez concedidos os pressupostos do empirismo reducionista de seu adversário, não seria possível determinar se um objeto sensível possui um dado predicado com mais razão que possui o predicado oposto. $\mathrm{O}$ fato dos vários Fs serem tratados indiferentemente como $\mathrm{F}$ e não-F é uma consequência da arbitrariedade do cenário projetado pelo amante dos sentidos, já que as diversas definições contextuais de $\mathrm{F}$ que este seria capaz de oferecer não estão unificadas por uma definição abstrata e independente de variações circunstanciais. No entanto, a definição de um conceito cuja univocidade não está garantida não pode gerar conhecimento - o que não significa que Platão deixa de reconhecer o valor de explicações e definições contextuais. Não obstante, é pela teoria das Formas que o autêntico filósofo subordina as diversas definições contextuais a uma definição abstrata que garante a univocidade do conceito definido, o que lhe permite articular todos os passos que explicam por que um certo objeto sensível, em uma circunstância determinada, possui um dado atributo e não seu oposto.

Em suma, o sucesso do argumento de 478e7-480a4 não se explica por serem suas premissas verdadeiras de modo incontroverso, mas pelo fato do adversário de Platão ser obrigado a aceitá-las em razão da epistemologia relativista que adota. Se o argumento é válido, o amante dos sentidos deve aceitar também a verdade da conclusão e renunciar à sua pretensão de conhecimento. Platão, por outro lado, não precisa acolhê-la. De fato, o autor da República não parece negar a cognoscibilidade dos sensíveis, mas apenas subordiná-la ao conhecimento das Formas. Afinal, mais adiante no diálogo, os verdadeiros filósofos, tendo contemplado o mundo das Ideias, serão convidados a voltar à alegórica morada dos que estão presos aos sentidos e conhecer, sobre cada sombra ali projetada, o que ela é e de que coisa ela é sombra (República VII, 520c1$5)$. 


\section{Referências}

\section{Obras de Platão}

Slings, S.R. (ed.) Platonis Rempublicam. Oxonii: E Typographeo Clarendoniano, 2003.

Duke, E. A., Hicken, W. F., Nicoll, W. S. M., \& Robinson, D. B. (eds.) Platonis Opera, tomus I. Oxonii: E Typographeo Clarendoniano, 1995.

\section{Literatura Secundária}

Allen, R.E. "The Argument from Opposites in Republic V" Review of Metaphysics 15 (2), pp. 325-335, 1961.

AnNas, J. An introduction to Plato's Republic. Oxford: Oxford University Press, 1981.

ANGioni, L. "Conhecimento Científico no Livro I dos Segundos Analíticos de Aristóteles" Journal of Ancient Philosophy Vol. 1 (2), 2007.

Bostock, D. Plato's Theaetetus. Oxford University Press, 1988. . Plato's Phaedo. Oxford University Press, 1986.

Brentlinger, J. "Incomplete Predicates and the Two-World Theory of the Phaedo" Phronesis, Vol. 17, No. 1, pp. 61-79, 1972.

BURNYEAT, M. The Theaetetus of Plato, with a translation by M. J. Levett, revised by Myles Burnyeat. Indianapolis and Cambridge, MA: Hackett, 1990.

Castañeda, H. N. "Plato's Phaedo Theory of Relations" Journal of Philosophical Logic 1, (1972), 467-480, 1972.

FINE, G. (ed.) Plato 1: Metaphysics and Epistemology. Oxford Readings in Philosophy. Oxford: Oxford University Press, 1999.

- (ed.) Plato on Knowledge and Forms: Selected Essays. Oxford: Oxford University Press, 2003a. 
- "Knowledge and Belief in Republic V" In: FINE, G. Plato on Knowledge and Forms: Selected Essays. Oxford: Oxford University Press, pp. 66-85, 2003b.

- "Knowledge and Belief in Republic V-VII" In: FINE, G. Plato on Knowledge and Forms: Selected Essays. Oxford: Oxford University Press, pp. 85-117, 2003c.

GAllop, D. Plato: Phaedo. Clarendon Plato Series. Oxford: Clarendon Press, 1975.

GEACH, P.T. “Good and Evil”'Analysis 17 (2), pp. 33-42, 1956.

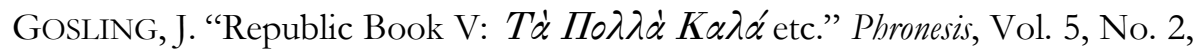
pp. 116-128, 1960.

IRWIN, T.H. "Plato's Heracleiteanism” Philosophical Quarterly 27 (106), pp. 1-13, 1967.

- "The Theory of Forms" In: FINE, G. (ed.) Plato 1: Metaphysics and Epistemology. Oxford Readings in Philosophy. Oxford: Oxford University Press, 1999.

KIRwan, C. "Plato and Relativity” Phronesis, Vol. 19, No. 2, pp. 112-129, 1971.

Matthen, M. "Plato's Treatment of Relational Statements in the Phaedo" Phronesis, Vol. 27, No. 1, pp. 90-100, 1982.

MCDOWELL, J. Plato: Theaetetus. Clarendon Press, 1973.

Mills, K.W. "Plato's Phaedo, 74b7-c6” Phronesis, Vol. 2, No. 2, pp. 128-147, 1957.

Murphy, N. R. The Interpretation of Plato's Republic. Oxford: Clarendon. Press, 1951.

NeHAmas, A. "Plato on the Imperfection of the Sensible World" In: FINE, G. (ed.) Plato 1: Metaphysics and Epistemology. Oxford Readings in Philosophy. Oxford: Oxford University Press, 1999.

Owen, G.E.L. “A Proof in the Peri Ideon” Journal of Hellenic Studies Pt. 1, pp.10311, 1957.

QuINE, W.V.O. Word and Object. Cambridge: MA- MIT Press, 1960. 
Ross, W. D. Plato's Theory of Ideas. Oxford: Clarendon Press, 1951.

SHIELDS, C. Classical Philosophy: A Contemporary Introduction London: Routledge, 2003.

Svavarsson, S. H. "Plato on Forms and Conflicting Appearances: the argument of Phaedo 74a9-c6" The Classical Quarterly, 59, pp. 60-74, 2009.

Vlastos, G. Platonic Studies. Princeton: Princeton University Press, 1973 a.

-. "Degrees of Reality in Plato". In: VLASTOS, G. Platonic Studies. Princeton: Princeton University Press, pp. 58-76, $1973 \mathrm{~b}$.

- "Reasons and Causes in the Phaedo". In: VLASTOS, G. Platonic Studies. Princeton: Princeton University Press, pp. 76-111, 1973c.

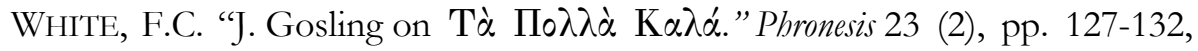
1978.

Zuppolini, B. A. "Forma Lógica das Proposições Científicas e Ontologia da Predicação: um falso dilema nos Segundos Analíticos de Aristóteles." Philósophos, v. 19, p. 11-45, 2014. 